\title{
EL LEGADO METAFÍSICO DE LAS COSMOGONÍAS. UNA TENSIÓN RECURRENTE ENTRE LAS CONCEPCIONES MONISTAS Y LAS PLURALISTAS
}

\author{
THE METAPHYSICAL LEGACY OF \\ COSMOGONIES. A RECURRING TENSION \\ BETWEEN MONIST AND PLURALIST VIEWS
}

\author{
ENRIQUE ROMERALES ESPINOSA* \\ Universidad Autónoma de Madrid
}

\begin{abstract}
Resumen: Todas las tradiciones del pensamiento religioso-filosófico poseen sus propios relatos sobre la Creación, sus cosmogonías. Aunque son muy diferentes entre sí, podemos agruparlos en dos tipos principales: los monistas y los pluralistas. Tras examinar diversos textos cosmogónicos capitales y clasificarlos en varios subtipos, constatamos que en muchos textos plausiblemente monistas persisten tendencias dualistas $y$, viceversa, que bastantes textos pluralistas contienen trazos monistas. Hay, pues, una tensión bastante generalizada entre la reducción a un principio único y la presencia de una pluralidad de principios. Pero la intuición metafísica subyacente a todos los relatos es que hubo un origen, una génesis, de forma que el universo no siempre ha sido como lo contemplamos ahora, sino que es producto de una generación y evolución.
\end{abstract}

Palabras Clave: Cosmogonía, Creación, mito, arché, metafísica, monismo, dualismo

AвSTRACT: All traditions of religious-philosophical thought hold their own narratives about Creation, their cosmogonies. In spite of being quite different to each other, they can be gathered into two main types: monist and pluralist cosmogonies. After surveying various relevant cosmogonist texts and classifying them into several subtypes,

\footnotetext{
* Departamento de Filosofía, Facultad de Filosofía y Letras, Universidad Autónoma de Madrid, c./ Francisco Tomás y Valiente 1, 28049, Madrid. Email: enrique.romerales@uam.es
} 
we find that dual trends persist in many plausibly monistic texts and, conversely, that numerous pluralist texts encompass monistic remnants. There is, then, a rather generalized tension between the reduction to a single principle and the presence of a plurality of principles. But the common metaphysic intuition underlying all these narratives is that there was an origin, a genesis, so that the universe has not always been as we observe it right now, but is the product of generation and evolution.

KEYwords: Cosmogony, Creation, myth, arché, metaphysics, monism, dualism

\section{Introducción: la pregunta por los orígenes}

La pregunta acerca de los orígenes constituye el nacimiento mismo del pensamiento humano, no solo de la filosofía, sino asimismo del pensamiento mítico y religioso, como nos pone de manifiesto la historia de las religiones. Es de sobra conocido que los primeros filósofos griegos se interrogaron por el arché, por aquel principio a partir del cual se habría originado todo, la abigarrada multiplicidad que observamos en nuestro universo. La respuesta inicial, la de las primeras generaciones de filósofos, apostó por la unicidad. Ya fuera el agua de Tales, el ápeiron de Anaximandro, el aire de Anaxímenes, o el ser de Parménides, todos convenían en que el origen y principio absoluto de la totalidad de lo real era algo único. Las generaciones posteriores, desde Empédocles hasta Leucipo y Demócrito, apostaron, en cambio, por un principio plural, ya fueran los cuatro elementos, los innumerables spérmata o los infinitos átomos. En todo caso, había unanimidad en un punto esencial: todo lo que contemplamos ha tenido un origen, un principio (singular o plural) desde el que se explica cómo es que el universo ha llegado a ser lo que es.

Pues bien, cuando nos asomamos a la historia del pensamiento a través de sus tradiciones religiosas, nos encontramos con una semejante duplicidad. Por un lado, existe una divergencia en cuanto a la cuestión de si ese principio, ese arché, es uno y único, o si más bien es plural. Por otro, existe unanimidad en cuanto a que existe un origen absoluto de todo lo real, una realidad originaria -denominada y tematizada de maneras, ciertamente, diversas- a partir de la cual se ha ido desarrollando todo lo existente. En lo que sigue, exploraré los relatos cosmogónicos centrales de las principales tradiciones religiosas en un intento de clasificar las diversas opciones, para poder ulteriormente extraer algunas conclusiones generales. 
Antes de comenzar con la "clasificación" de los relatos cosmogónicos en términos de tipologías, son pertinentes ciertas observaciones. La primera, es que lo que nosotros consideramos como un texto unitario, como un libro, ya sea el Enuma Elis, el Génesis o el Rg Veda, no es sino una superposición de capas de textos, que por lo general se transmitieron primero de forma oral, luego se transcribieron, y después se fueron modificando. De manera que desde la composición de las partes más antiguas del relato hasta la versión final que nos ha llegado transcurrió mucho tiempo, a menudo varios siglos, con la consiguiente reelaboración del texto. Esta reelaboración no suele acabar con una "edición" más o menos sistemática y coherente de los contenidos del texto, sino que contiene adiciones, yuxtaposiciones, repeticiones y mutilaciones, que hacen de los relatos cosmogónicos en la mayoría de los casos algo harto confuso, cuando no directamente caótico.

A consecuencia de lo anterior, en muchos de estos venerables textos se entrecruzan diversos relatos y mitos cosmogónicos, que más que complementarios parecen mutuamente inconsistentes. Esto es singularmente el caso en los textos del hinduismo, no solamente en el más arcaico de sus libros, el $\mathrm{Rg}$ Veda, sino asimismo en los restantes Vedas y también en los ulteriores Upanishads, repletos muchos de ellos de mitos cosmogónicos.

En tercer lugar, incluso en aquellos textos que contienen un relato unificado, más breve y coherente sobre los orígenes, como por ejemplo el Enuma Elis, hay enunciados ambiguos, vagos o, cuando son más claros y precisos, en disonancia con otros enunciados del mismo relato. Esto hace que a la hora de clasificar un relato cosmogónico tengamos que referirnos, no ya al "libro" como un todo, ni siquiera a un relato o mito cosmogónico en particular dentro de él, sino a un pasaje o fragmento concreto dentro de ese relato, en donde se afirma algo explícito acerca del principio, del arché, y de cómo surgió lo demás a partir de él.

Una última observación: la incongruencia en un relato cosmogónico es un problema para nosotros, que buscamos en el texto la respuesta a nuestra pregunta, filosófica y humana, sobre el origen último de lo real. Pero para muchos de quienes contribuyeron a la composición del texto, incluyendo sus "editores" finales, tal preocupación podía ser mucho menor cuando la finalidad primordial del texto no era tanto filosófica, o metafísica, sino antes bien histórica y política. Porque en varios de estos textos el objetivo del relato es ensalzar a una divinidad determinada y, correlativamente, a su templo principal, a la ciudad que lo acoge, 
como axis mundi, y, de paso, a los sacerdotes custodios de ese templo y de sus rituales sacrificiales. Así ocurre con uno de los más célebres poemas cosmogónicos, el más antiguo (al menos entre los mesopotámicos) de los conservados casi completos: el Enuma Elis. El filósofo rebusca en él su cosmogonía, que es por donde comienza; pero el historiador de la religión sabe que el protagonista del relato (Marduk) y el sentido del texto mismo se halla en el desenlace. Marduk ha vencido a las fuerzas oscuras primigenias (predivinas), y ha instaurado el orden celeste (cosmología). Su templo en Babilonia se convierte en axis mundi, y sus sacerdotes en autoridad suprema y en fuente del orden terrenal. El interés histórico-político es, si bien no la única, sí la principal finalidad del mito ${ }^{1}$. De manera que el verdadero protagonista del texto es aquel dios, posterior en varias generaciones al Creador o a los Creadores iniciales, que tras acometer determinada excelsa empresa (vencer a un monstruo, conquistar un reinado, derrotar al principio y príncipe del mal etc.) y una vez finalizada con éxito su inconmensurable hazaña, se erige en gobernante supremo del universo. Porque, efectivamente, una gran parte de las cosmogonías están trufadas de teogonías, y la finalidad religiosa, o religioso-política del texto, suele preponderar sobre la especulación

1 “... el Poema de la creación [Enuma Elis]. Lo llamamos así de manera bastante impropia, pues su objetivo no era en absoluto básicamente teogónico, cosmogónico o antropogónico, si bien tocaba en efecto este triple capítulo... se trataba de demostrar que Marduk, llegado tarde al panteón... y apenas conocido antes del segundo cuarto del segundo milenio, había merecido llegar a ser el primero de los dioses, su soberano, y señor del mundo y de los hombres" (Bottéro, 2001, 112-113). La maniobra del autor del poema para colocar a Babilonia en el centro geográfico-político está muy bien explicada por T. Frymer-Kensky y G. Pettinato (2005, 2.810-11): "All the Sumerian traditions assigned the position of principal god in their pantheon to Enlil. But at the same time they emphasized that the first seat of the kingship before the Flood was the city of Eridu, the home of the god Enki, who was thus regarded as the first holder of royal power on earth. Hence the scribes decided to make Marduk the son of Enki. Their syllogistic reasoning thus becomes quite clear: if Enki the king is Marduk's father, then Marduk becomes the king. In addition, if Eridu is the home of Enki and the place of his kingship, then Babylon, the home of Marduk, is automatically the one true location of the kingship... With this delicate substitution the Babylonians manage to establish their city as the first human urban settlement". Y al igual que la ciudad era el centro de la Tierra, el templo ha de serlo dentro de la ciudad, justificándose así el esplendor y la prominencia socio-económica que adquiere el templo y el complejo de edificaciones que lo rodean, lo que ocurrió no solo en Babilonia con Marduk, sino también en otras ciudades mesopotámicas con sus respectivos dioses: "Temples were usually the largest and most imposing structures in a community... Babylonian temples often controlled important economic resources... Temples could act in the community as proprietors, investors and employers" (Foster, 2007, 193). 
metafísica abstracta ${ }^{2}$. Esto hace que el inicio del relato, donde se cuenta cómo empezó todo -que es lo que nos interesa qua philosophos-para los autores del texto sea en muchos casos casi una simple excusa para construir la genealogía del verdadero protagonista, del héroe, y a la vez para mostrar su excelso pedigrí ${ }^{3}$.

\section{Relatos cosmogónicos pluralistas}

Comenzaré por aquellos relatos cosmogónicos, sin duda mayoritarios entre las grandes tradiciones religiosas, que nos remiten a más de un principio originario. Los subdividiré en cuatro grupos: las cosmogonías de reproducción por fecundación, las de creación por combinación de tres principios, las cosmogonías de extracción (desde el abismo), y las cosmogonías de fabricación (por un architekton o demiurgo). Insisto en que dentro de un mismo mito pueden aparecer varios de estos tipos en diferentes pasajes del relato, amén de que en algunos casos la interpretación de ciertos enunciados no está ni mucho menos clara.

Empiezo con las cosmogonías que expresan un modelo de reproducción por fecundación. Este modelo es perfectamente natural, pues nada nos es más cercano en cuanto al origen que el nacimiento de nosotros mismos, mediante la fecundación de la hembra por el macho en la copulación. Este modelo biológico de los vivíparos se exporta al universo, generalmente mediante una metáfora en términos geológicos o astronómicos. Así, el Enuma Elis comienza afirmando que Apsu (las aguas dulces, de la lluvia, de los ríos y de los acuíferos) fecunda a Tiamat (las aguas saladas, del profundo océano). El primero es el agua transparente, cristalina, potable. La segunda el agua oscura, insondable, imbebible. Apsu representa el orden, lo masculino; Tiamat la turbulencia, el caos, lo femenino. Estos dos principios, de los que subsiguientemente se generarán todos los demás seres, incluidos los dioses y más tarde los hombres, no son ellos mismos dioses, sino

2 En el $R g$ Veda, donde abundan los mitos cosmogónicos, ello se enmarca dentro de los himnos de loa y gratitud a un determinado dios. En el cap. CXXI del libro X, tras haber ensalzado a varios dioses, el estribillo repite: “¿A qué dios adoraremos con nuestra ofrenda?” (Griffin, 1896, http://www.sacred-texts.com/hin/rigveda/rv10121.htm).

3 El protagonista puede ser el dios-gobernante supremo del universo, como en el caso de Marduk en el Enuma Elis, o puede ser un héroe humano, como en el caso de Atrahasis, en el poema que lleva su nombre. En otros casos, las hazañas del héroe no necesitan remontar el relato hasta los orígenes, con lo cual no aparece cosmogonía alguna. Así ocurre en el poema de Gilgames, o en los relatos sobre Noé en el Génesis. 
algo antecedente: los principios originarios absolutos, previos a cualquier dios. Es solo la coyunda de esos principios indiferenciados iniciales, de Apsu y Tiamat, la que da origen a la segregación de las fuerzas primigenias de la naturaleza, en adelante identificables mediante nombres propios: los diversos dioses del panteón mesopotámico. Y así hasta llegar al verdadero protagonista, el dios Marduk, que tras enfrentarse y vencer a la terrible y brutal Tiamat, crea el cosmos, vale decir, instaura un orden astronómico, espacial y temporal, donde aún no lo había, y comienza a regir ese universo.

Este modelo de fecundación vivípara se da en otros importantes relatos cosmogónicos. Así, en la Teogonía de Hesíodo ${ }^{4}$ Urano, el Cielo, fecunda a Gea, la Tierra, de cuya unión van saliendo numerosos hijos, incluido Crono. Hasta que Zeus se convierta en soberano de la caterva de los dioses. De modo semejante, en algunas religiones de Papúa Nueva Guinea el Cielo fecunda a la Tierra, o también ocurre lo propio en el relato cosmogónico japonés Nihongi ${ }^{5}$. Es muy frecuente que el principio receptor, femenino, sea la Tierra, y que el principio fecundador, masculino, sea un elemento que viene de arriba, ya sea el Cielo, la Atmósfera, como en los dos casos recién mentados, o las aguas dulces (lluvia, deltas), como en el Enuma Elis. Esta dualidad de principios de géneros opuestos puede representarse también de modo biológico en vez de astronómico-geológico. Es de destacar que, siguiendo así mismo un modelo de creación biológico, otras cosmogonías emplean en cambio la imagen de los ovíparos. Así, en varios Upanishads, como veremos, aparece el tema del huevo cosmogónico.

Un segundo tipo de cosmogonías es aquel en el que la creación se produce por combinación de varios principios, sin que haya una atribución tan clara de roles entre ellos, ni un modelo biológico imperante como en los casos anteriores. Así, en el poema de Atrahasis ${ }^{6}$ aparecen al inicio tres principios: Anu (el Cielo),

4 Sin embargo, en la Teogonía la fecundación de Gea por Urano no es el momento inicial. En principio era el Caos (por ello incluiremos a la Teogonía también dentro de los relatos cosmogónicos monistas). Luego -sin que se indique cómo ni de dónde- aparecen Gea y Eros (fuerzas primordiales, más bien que divinidades). Explícitamente del Caos surgen Érebo y la negra Noche, y de estos Éter y Hémera. Solo entonces Gea da luz a Urano, quien fecundándola engendrará a los dioses propiamente dichos y a los titanes, hasta llegar a Crono (Teogonía, 117-135).

5 "El Cielo, por consiguiente, se formó primero y la Tierra se afirmó a continuación. Entre ambos fueron producidos después los seres divinos" (Nihongi, trad. W. G. Aston, Londres, 1924; en Eliade, 1980, 106).

6 Se trata del poema cosmogónico mesopotámico más antiguo, pero conservado de forma muy fragmentaria (cf. Bottéro \& Kramer, 2004, 541 y ss.). De nuevo el verdadero prota- 
Enlil (la Tierra) y Ea (las aguas), y mediante su combinación se genera el mundo. Es curioso que este texto, que acaso sea el más antiguo de cuantos relatos cosmogónicos poseemos, al proponer un modelo múltiple de principios originarios (en este caso tres) concuerde con el pluralismo que en nuestra tradición filosófica occidental se desarrolló dos siglos después de las primeras propuestas, todas ellas monistas. Me refiero, por ejemplo, a Empédocles, con su doctrina de los cuatro elementos ${ }^{7}$, o a Anaxágoras con su teoría de la multiplicidad innumerable de los spérmata.

Un tercer tipo de cosmogonías son las que podríamos denominar "de extracción”, desde el abismo. Aquí el modelo biológico de trasfondo parece ser no la fecundación, sino el parto. Así, según un mito de los indios navajos norteamericanos, el mundo habría surgido del fondo ilimitado de las entrañas de la Tierra (se supone que los ancestros vivían en las profundidades de la Tierra, pero lograron salir a la superficie y organizar el mundo). Es, empero, más frecuente que ese abismo insondable se represente de forma fluida antes que compacta, surgiendo la pluralidad de entes de la profundidad del océano. A modo de ejemplo, el motivo del buceador de la Tierra aparece en diversas versiones en distintas tribus de indios en California. Según los maidus, una divinidad (llamada Iniciado de la Tierra) envía a una tortuga para que extraiga una partícula de Tierra a partir de la que se acabará formando todo el universo. Según los yauelmanis, una divinidad (un águila) envía a un pato para que extraiga la tierra del fondo del mar (cf. Eliade, 1980, 100 y ss.). En otros relatos son otros animales (serpiente, dragón, aves diversas) los que se sumergen, cuando no la divinidad misma, hasta el fondo del océano primordial para extraer el barro a partir del cual crear tierra firme. En estos relatos el protagonista haría las funciones de "comadrona", ayudando a extraer desde el fondo (Tierra, Océano etc.) aquello que en germen ya se encontraba allí.

Por último, tenemos las cosmogonías de fabricación, en las que alguien inteligente, un arquitecto o demiurgo, se encarga de organizar un material que preexistía, pero en un estado amorfo. En estos casos tenemos al menos dos principios: el arquitecto y la materia; y en ocasiones un tercero. Así, en el relato maya quiché de la creación, el Popol Vuh, se afirma que los creadores, Tepeu y

gonista se halla al final: Atrahasis, el muy-sabio, quien salvó a los hombres de la destrucción divina y del diluvio.

7 Aunque habría que matizar, pues cuando la mezcla es perfecta en el punto culminante de un universo regido por el eros, se da la sphairos, que es la perfecta y homogénea fusión de dichos elementos. 
Gucumatz, procedieron así sobre la indiferenciación originaria del océano inmóvil y el cielo vacío: "Que se llene el vacío. Que esta agua se retire, que surja la tierra y que se afirme... solo con ser dicho y mandado se formó la tierra. Tierra, dijeron, y al instante fue hecha"8. Otro ejemplo: en las Leyes de Manu se afirma que Brahma dispersa las tinieblas y produce el agua (Eliade, 1980, 123). Y un último: en el Timeo (29a y ss.) Platón afirma que es el Demiurgo quien forma el cosmos al imprimir las Formas (eternas) en el espacio-materia (asimismo eterno).

\section{Relatos cosmogónicos monistas}

Los relatos cosmogónicos que podemos calificar de (o interpretar como) monistas también presentan una importante diversidad. Los clasificaré en tres tipos: las cosmogonías de escisión (partenogénesis), las de descomposición y las de creación. Las primeras siguen también un modelo biológico, típico a nivel celular, pero mucho más extraño entre los organismos macroscópicos, si bien hay organismos cuya división produce una duplicación, como ciertos gusanos. Como dicha escisión suele representarse como una división en dos, como una genuina partición, esa dualidad subsiguiente es a menudo traducida en términos de las oposiciones ya conocidas: cielo y tierra, macho y hembra, yang y yin, etc. Las cosmogonías de descomposición son aquellas en las cuales el todo no se divide en dos "mitades" equipotentes, sino que se rompe o desparrama en múltiples pedazos. Estos restos son la multiplicidad que surge, y la unidad originaria resulta destruida. Comoquiera que muy a menudo el relato se entiende en términos antropomórficos, la destrucción de la unidad originaria se traduce como muerte del ser primordial, y el deceso de tal ser, antropomorfo, se interpreta como el Gran Sacrificio necesario para la creación del universo. Sacrificio que tendrá consecuencias obvias en el ulterior desarrollo de las prácticas religiosas, y que se rememorará y revivirá en los ritos sacrificiales de la religión correspondiente. Finalmente el modelo de la creación, que nos es el más cercano, es aquel en el que un principio supremo, omnipotente y sabio, crea todo sin que exista una materia previa, o bien ex nihilo, o bien a partir de sí mismo por alguna suerte de emanación o excrecencia, pero sin que ello suponga menoscabo o disminución en su ser o en su poder, y mucho menos su extinción, como en el caso anterior.

8 Popol Vuh, 2008, 58. Podría pensarse en clasificarla como cosmogonía de extracción, pues la Tierra emerge de las aguas. Pero nadie se sumerge para sacarla: ¡el creador (dual) crea con su sola palabra! Más abajo veremos el elemento monista en este relato. 
Comenzando por las cosmogonías de escisión, tal tipo es frecuente en la tradición hinduista. Así, en el más antiguo, extenso y venerable de los Upanishads, el Brhadaranyaka (I, 4, 3), se afirma que la unidad originaria, Brahman (lo Absoluto) se escindió en lo masculino y lo femenino'. En otro de los mayores Upanishads, el Chandogya (III, 19) se explica la división en dos del huevo cosmogónico universal (Upanishads, 1995, 65). Esta idea del huevo cosmogónico, ajena a las anteriores cosmogonías del $\mathrm{Rg} V e d a$, que obviamente es una metáfora extraída del modelo ovíparo de reproducción, aparece ulteriormente de diversas formas en muchos textos del hinduismo a lo largo de los siglos. Primero poco antes de nuestra era en las Leyes de Manu, y más tarde, en nuestra Edad Media, algunos Puranas reelaboran la idea ${ }^{10}$. Tema que, por otra parte, es común a relatos cosmogónicos persas, siríacos, egipcios y órficos griegos.

Hay que destacar, empero, dos cosas. En primer lugar, que en muchos casos el huevo cósmico del que sale el universo no constituye el momento inicial absoluto, sino un momento subsiguiente al estadio primero absoluto representado por la realidad suprema, llámesele Brahman -en los textos del advaita Vedanta- o Vishnú -en los textos teístas que reivindicará la tradición visishadvaita de, entre otros, Ramanuja-. Es algo semejante a cómo el Big Bang ahora parece ser solamente el estado inicial de nuestro universo, pero no el origen absoluto del tiempo, sino algo surgido en un momento de la "historia" del multiverso (repárese, sin embargo, en una diferencia: el Big Bang supone una violenta explosión en innumerables componentes, mientras que la idea del huevo cósmico es la de una división en dos, que representa una transición "natural" y generalmente no catastrófica ni traumática, como una eclosión).

En segundo lugar, no todos los relatos del huevo cosmogónico hablan de una división de la que surge la dualidad. En algunos casos el huevo lleva en su interior

9 "Al principio este mundo era solamente atman en forma de purusha... Deseó, pues compañía. Ciertamente, era tan grande como un hombre y una mujer unidos en íntimo abrazo. Hizo, pues, que su ser cayera partido en dos. De aquí surgieron el marido y la mujer" (Ilárraz \& Pujol, 2003, 225).

10 Así en el Visnú Purana (I, II) se afirma: "Al principio, el universo estaba lleno de agua. Pero en esa agua surgió un enorme huevo (ANDA), que era redondo como una burbuja de agua. El huevo se hizo más y más grande y en el interior del huevo se hallaba Vishnu. Este huevo fue llamado Brahmanda. Y dentro de Brahmanda estaban las montańas y la Tierra, los océanos y los mares, los dioses, los demonios y los seres humanos y las estrellas. Por todas partes, el huevo estaba rodeado de agua, el fuego, el viento, el cielo y los elementos. En el interior del huevo, Vishnú adoptó la forma de Brahma y procedió a crear el universo" (Visnú Purana, 1840, 18-19). 
al dios Brahma, que al salir de él construye u organiza el universo. En tales casos, el relato no se encuadra bajo nuestro epígrafe de "cosmogonías de escisión", porque se trata en realidad de una eclosión, de un nacimiento del ser que anidaba en el interior del huevo. El subsiguiente acto de creación/organización cósmica por parte de Brahma suele ser a partir de una materia que ya se había segregado de la unidad originaria, aunque también hay casos en que es el propio Brahma quien produce la materia a partir de sí mismo.

Esta idea recurrente de la escisión para explicar el origen se halla por doquier. Así, como señalábamos, en uno de los mitos centrales de la tradición del shinto japonés, los relatos Kohiki Nihongi, se narra la separación o escisión del Cielo y la Tierra, progenitores del mundo que se hallaban fusionados. También en la propia Teogonía de Hesíodo, como veíamos, el inicio absoluto parece ser unitario: el vacío abismal, que existía antes de todo ${ }^{11}$. Ciertamente, son numerosas las cosmogonías en las que en principio solo hay un "magma”, un ápeiron amorfo, referido de formas diversas: caos, vacío, océano, abismo, tinieblas, etc. De esta forma, en la cosmogonía del Popol Vuh esa unidad indiferenciada lo forman el océano y el cielo: "No se manifestaba la faz de la tierra. Solo estaban el mar en calma y el cielo en toda su extensión. No había nada junto, que hiciera ruido, ni cosa alguna que se moviera... No había nada dotado de existencia, no había cosa que tuviese ser. Solamente había inmovilidad y silencio, en la oscuridad, en la noche"12. O en el Tao te Ching (IV, 48): "El Tao es vacío, mas su eficiencia nunca se agota. Es un abismo, parece raíz de todos los seres" $(2006,386)^{13}$. Incluso el Enuma Elis, que hemos calificado como cosmogonía dualista, posee

11 "En verdad lo primero de todo fue caos, y luego Gea..." $(2014,19)$. Es problemático qué significa 'Xóoç'. G.W. Most traduce "Abismo" [Chasm], y explica: "en general traducido como 'caos', pero eso nos sugiere, desorientándonos, un revoltijo de materia desordenada, mientras que el término de Hesíodo indica, en vez de eso, un hiato o apertura", $(2006,76)$. En la misma línea, P. Mazon: "Avant tout, fut Abîme”; y en nota añade: "O también el Vacío. Xóos designa una profundidad abierta [béante]. El poeta se representa el espacio que separa el cielo y la tierra prolongado indefinidamente, dado que ni el cielo ni la tierra lo limitan aún ni por arriba ni por abajo" $(1967,36)$.

12 Popol Vuh, (2008, 57; cf. asimismo 177-8). Pero si arriba clasificamos este relato como pluralista, es porque acto seguido se afirma: "Solo el Creador, el Formador, Tepeu, Gucumatz, los Progenitores, madre y padre, estaban en el agua rodeados de claridad... De esta manera existía el cielo y también el Corazón del cielo, que este es el nombre del dios." O sea: magma primordial (agua-cielo), pero también Creador cabe él (Tepeu-Gucumatz).

13 En la versión primitiva del texto, el Lao zi de Guodian, hallada en 1993, el cap. XXV reza: "Hay una cosa confusamente formada anterior al Cielo y a la Tierra. ¡Silenciosa, ilimitada! De nada depende y no sufre mudanza, puede ser tenida por madre del mundo. Su nombre desconozco, su ideograma es Tao" (2006, 167). La versión clásica es casi idéntica. 
cierta ambigüedad, pues al inicio del poema se afirma que cuando no había nada más que Apsu y Tiamat, "Mezclaban, juntos, sus aguas"14. Y aquí, según donde coloquemos el énfasis, podemos entender que se trata de una unidad originaria donde en potencia anida la dualidad ${ }^{15}$; pero también, a la inversa, que lo originario es la dualidad, que se halla como "dormida", agazapada -por lo general de forma temporal y recurrente- en una unidad que no es primigenia y absoluta, sino derivada y relativa. Es así como puede explicarse la gran cuestión que han de afrontar las doctrinas monistas radicales: ¿por qué lo absoluto, llámesele Brahman, Dharmakaya, Tao, Uno, Dios, En Sof o como fuere, no permaneció por siempre jamás en su sagrada y beatífica unicidad? Las doctrinas ex profeso dualistas resuelven este problema: lo originario es la dualidad, la tensión, la bipolaridad -la dialéctica, si se quiere- y por ello el movimiento ${ }^{16}$, aunque haya largos períodos de reposo. Por eso, creo, las metafísicas dualistas son frecuentes en, y acaso se compaginan mejor con, las tradiciones que conciben el tiempo de forma cíclica, como ocurre en el Extremo Oriente. Mientras que para las tradiciones religiosas del Oriente Medio, las tradiciones (mal) llamadas del Libro, lo de suyo, lo kata autó, es la Eternidad, y el tiempo es una suerte de "anomalía" difícilmente comprensible (si es que es en absoluto inteligible) y que, en todo caso, acontece una única vez. A pesar de lo cual, incluso dentro de estas tradiciones monoteístas, en ocasiones la negatividad "se cuela" en Dios para poder explicar el tiempo y el devenir.

Paso a continuación al segundo tipo de cosmogonías monistas: las cosmogonías de descomposición. Como señalé anteriormente, es frecuente que esta descomposición sea interpretada en términos biológicos, de un animal o, más específicamente,

14 Bottéro \& Kramer $(2004,618)$. Sin embargo, Feliu y Millet, en la versión directa más reciente al español, traducen: "Cuando mezclaron sus aguas...", con lo que se colige que la separación era ya su estado original (Enuma Elis, 2014).

15 Esta idea de lo negativo que anida en el ser o en Dios se ha expresado en diversos autores y tradiciones. Es la nada que se halla en el interior del En Sof, de los cabalistas judíos; la negatividad que se halla en el seno de Dios, de Hegel; la nada que anida en el ser, de Heidegger etc. Quienes, como Parménides, se niegan a dotar de la más mínima realidad a la negatividad, al no ser, se ven obligados a negar el devenir, y con ello la existencia misma del universo. Es lo que dentro del Vedanta también hicieron Gaudapada y luego Shánkara, con su doctrina de que, según el nivel de la verdad suprema, solo existe lo Uno, Brahman; doctrina que von Glasenapp denominó acertadamente "acosmismo" (1977, 202 y ss.).

16 Acaso nada exprese mejor este permanente dinamismo, esta tensión de dos polos que se complementan e incitan mutuamente, que la doctrina taoísta (¡y la representación gráfica!) del yang y el yin. Cada uno se introduce en el otro, y al hacerlo lo dinamiza, y así ambos forman un círculo perfecto, en perpetuo girar. 
de un ser antropomorfo, que se descompone, que se desmiembra, para de sus partes dar lugar al universo. Es el mito del andrógino primordial (el Purusha ${ }^{17}$ ) que aparece el $\mathrm{Rg}$ Veda, pero también posteriormente en varios relatos cosmogónicos del Atharva Veda, de algunos Brahmana, y de diversos Upani-shads ${ }^{18}$. Su inmolación ha permitido nuestra existencia. Su sacrificio representa la entrega suprema. También en el cristianismo hay un hecho sacrificial divino en beneficio del mundo: «Tanto amó Dios al mundo que entregó a su Hijo único para que no perezca ninguno de los que creen en él, sino que tengan vida eterna» $(\mathrm{Jn} 3,16)^{19}$. De esta manera, la celebración en memoria del sacrificio del Purusha se convertirá en momento central del rito sacrificial (y posteriormente del culto) en la tradición hinduista.

Este modelo de la extrema generosidad del ser primordial que se sacrifica para dar lugar al mundo tiene variantes en las que el ser primordial es sacrificado. Así ocurre en el mito escandinavo de Ymir mit, uno de sus principales relatos de la creación, cuya historia aparece en el poema Vafthrúdnismál, recogido en la compilación medieval de poemas Edda. El gigante Ymir es una víctima antropomórfica que tras morir ${ }^{20}$ es desmembrada por Odín y sus dos hermanos, y de cuyos despojos van surgiendo las diferentes partes del mundo: de su cerebro las nubes, de sus cabellos los árboles, de su sangre el mar, etc. (cf. Davidson, $197-$ 201; Lindow, 2002, 322-326). También en el Enuma Elis, ya avanzado el poema, es el desmembramiento de Tiamat, por parte del joven y aguerrido dios Marduk, lo que posibilita que a partir de sus restos Marduk configure el universo, y genere un cosmos donde antes no existía. Si bien, en este caso, hay una historia previa, de modo que el origen "del cosmos" (las estrellas, los planetas, el sucederse de las estaciones, del día y la noche) no coincide con el inicio de todo lo real, sino

17 Purusha se ha traducido de diversas maneras: la Persona (originaria), el Andrógino, el Hombre (primordial), incluso el Espíritu, etc. Es el principio creador inteligente, masculino, opuesto a la materia amorfa (prakriti), lo femenino. Sobre los significados y las funciones del Purusha en los mitos cosmogónicos en los Vedas y en los Upanishads, ver Ilárraz y Pujol (2003, 49-53 y 63-69).

18 El Locus classicus es el $\mathrm{Rg}$ Veda, X, 90. En los Upanishads aparece reiteradamente, aunque en los posteriores el purusha se espiritualiza. Así en el Mundaka (II, 1, 2) se afirma del purusha: "es resplandeciente, sin forma... no nacido, sin mente, puro, más elevado que el elevado imperecedero" (Ilárraz \& Pujol, 2003, 133). Para la transición de los mitos cosmogónicos del Rg Veda a los Upanishads, puede verse J. Arnau (2012, 35-51).

19 Si bien es cierto que la cita referida de este evangelio tiene un significado soteriológico, y no propiamente cosmogónico; el Hijo se entrega y sacrifica para la redención, no para la creación del mundo.

20 En la versión del Edda en prosa, son Odín y sus hermanos quienes asesinan al gigante, provocando una catástrofe (la inundación del mundo con su sangre) y con cuyos restos componen la Tierra y el Cielo (cf. Littleton, 2004, 276-728; Eliade, 1979, 159-160). 
que sucede en una fase ulterior. Así, el Enuma Elis, en cuanto cosmogonía sensu stricto, constituiría una cosmogonía de descomposición, pero en el sentido lato de origen absoluto de todo lo real, sería una cosmogonía dualista.

En tercer y último lugar dentro de las cosmogonías monistas se hallan las cosmogonías de creación. En ellas un ser supremo crea el mundo con el pensamiento, por la palabra, o, en otros relatos más primitivos -o si se prefiere, más imaginativos- calentándolo en una sauna, moldeando una masa dúctil amorfa (de barro, de maíz... $)^{21}$. Así, según el Génesis, Dios crea el mundo en seis días o etapas. Algo que se repite en el Corán (6, 1-2). También en el $R g$ Veda (XI, 81) aparece Visvakarman, el "hacedor de todo". En el Chandogya Upanishad, (VI, 2) se nos relata que el Ser Puro crea con el pensamiento ${ }^{22}$, o en el posterior Brahma Purana, al inicio, se nos informa de que Brahma, tras crear el Cielo y la Tierra, produce vástagos de su mente, que a su vez conforman el universo.

\section{Relatos cosmogónicos de difícil clasificación}

Hasta aquí he recogido una muestra de relatos cosmogónicos que he intentado clasificar para hacer una suerte de tipología de las cosmogonías. Sin embargo, hay textos, incluso algunos muy relevantes, que difícilmente encajan en nuestra tipología. Por un lado, hallamos el sorprendentemente escueto relato del Tao te Ching (XLII): "El Tao engendra al uno, el uno engendra al dos, el dos engendra al tres, el tres engendra a los diez mil seres" ${ }^{23}$. Tan escueto que podríamos denominarlo "anticosmogonía". No en el sentido de negar explícitamente que la totalidad de lo real se haya originado a partir de algo -en este caso de un único principio supremo, el Tao, tratándose entonces de una cosmogonía (o más bien metafísica) monista- sino en el sentido de que no cabe siquiera intentar relatar el cómo.

21 Naturalmente, cuando existe algún material previo independiente que modelar, será dualista más que monista. Sin embargo, no siempre está claro el estatus ontológico de este putativo material previo, a menudo referido como "vacío", "nada", "tinieblas", "oscuridad", etc.

22 Esta idea de que la divinidad crea con el solo pensamiento, sin esfuerzo, sin "mancharse", aparece en tradiciones diversas. En los indios omahas: "Al principio todas las cosas estaban en la mente de Wakonda [el hacedor de todo]. Todas las criaturas, el hombre también, eran espíritus" (Eliade, 1980, 96). También, vimos, en el Popol Vuh.

23 Tao Te Ching, 2006, 227. Se trata de la versión clásica del libro, el Lao zi de Mawangdui.

ÉNDOXA: Series Filosóficas, n. ${ }^{\circ}$ 36, 2015, pp. 11-30. UNED, Madrid 
Un segundo texto intrigante es el célebre $\operatorname{Rg}$ Veda X, 129:

Ni no ser ni ser había entonces; no había el espacio, ni el cielo sobre él... Alentaba sin viento según su propia ley aquello que era uno. Algo más, distinto de él, no había. Tinieblas había, envueltas en tinieblas, al principio; una marea indiscernible era aquel todo. La nada que estaba encerrada en el vacío, por el poder del ardor nació como lo uno... Esta creación de dónde viene, si fue hecha o no, aquel que vigila en el cielo más alto, tal vez él lo sepa, a no ser que ni siquiera él lo sepa. ${ }^{24}$

Aunque de difícil clasificación, por su carácter paradójico, pienso que el texto puede considerarse esencialmente monista: el origen absoluto es lo Uno, que es el todo; indiscernible, indiferenciado, envuelto en tinieblas. Si bien, acto seguido se añade que lo uno nació de la nada, que a su vez anidaba en el vacío. Sería, entonces, el vacío el Grund fundamental y originario, de la nada y, subsiguientemente, del Todo-Uno. Lo misterioso, lo que queda en interrogación, es cómo (es que) surgió la multiplicidad del todo unitario -si es que en verdad salió-, y si alguien en absoluto lo sabe. Este halo escéptico del final (otros traducen la última frase: “¿o ni siquiera él lo sabe?”), ha hecho pensar a los investigadores que con gran probabilidad se trata de uno de los cantos más tardíos del $\mathrm{Rg}_{\mathrm{V}} \mathrm{ed}{ }^{25}$. En todo caso, se trata de un texto enormemente complejo, profundo y oscuro a la vez, que ha recibido múltiples y notablemente divergentes interpretaciones ${ }^{26}$.

Y, por último, recabo un relato de la cosmogonía polinesia donde se expresa una doctrina sorprendente: la autocreación, pues el ser primordial se habría generado a sí mismo:

Ta’aroa fue el antepasado de todos los dioses; él hizo todas las cosas. Desde tiempo inmemorial existió el gran Ta’aroa, Tahi-tumu (el origen). Ta’aroa

24 Cito la traducción de Ana Agud (Agud, 1995, 20). Para una edición completa con comentarios, ver The Rig Veda (2014; nuestro himno es comentado en la p. 1607).

25 Aun así, sigue siendo arcaico, presumiblemente del siglo X a. C., y por consiguiente varios siglos anterior al poema de Parménides, que contiene sorprendentes semejanzas (aunque Parménides es plenamente asertivo; al fin y al cabo son las Musas quienes le han desvelado la verdad). En el poema de Parménides habla un oráculo, mientras que en el texto del Rg Veda ¡habla un filósofo!

26 Como ha puesto de manifiesto Joel Brereton (Brereton, 1999, p. 248 y ss.). La suya (p. 259) es que el enigmático texto constituye un acertijo, que al incitarnos a pensar sobre la impensabilidad del origen, nos ubica en el pensamiento mismo como origen de todo. 
procedió a partir de sí mismo, en entera soledad; él fue su propio progenitor, sin padre ni madre... Ta'aroa estaba sentado en su concha, en las tinieblas, desde toda la eternidad. La concha era como un huevo que daba vueltas en el espacio infinito, sin cielo ni tierra ni mar ni luna ni sol ni estrellas. Todo era tiniebla, una espesa y continua oscuridad... Pero Ta’aroa logró romper su concha, que se convirtió en bóveda celeste, nadó hacia el espacio vacío y se retiró a una nueva concha de la que salió otra vez... Convirtiéndola... en el gran cimiento del mundo, la roca y el asentamiento del mundo... La concha Rumia, de la que salió la primera vez, se convierte en su casa, la cúpula del cielo de los dioses, que era un cielo cerrado en cuyo seno estaba entonces el mundo en formación ${ }^{27}$.

Lo verdaderamente sorprendente aquí es que una hipótesis de este tipo, tan extrańa como apasionante, y que puede interpretarse en el sentido de que Ta'aroa se hallaba ya encapsulado en el interior de sí mismo, es decir, que el texto proclama una suerte de autocreación, está siendo reivindicada en algunas teorías cosmológicas actuales sobre el origen del universo. De este modo, si fueran posibles los viajes en el tiempo, quizá el origen del cosmos hubiera consistido en un gigantesco viaje temporal, un bucle en el que el universo se habría creado a sí mismo. No podemos ignorar que la posibilidad de viajar en el tiempo resulta actualmente muy controvertida entre los físicos y $\operatorname{cosmólogos}^{28}$, pero es igualmente cierto que algunos de los más eminentes la han utilizado para dar cuenta del origen absoluto del universo. Este es el caso del físico de Princeton Richard Gott, cuyas palabras refiero:

Hoy creemos que el universo comenzó tras un estado de expansión muy rápida denominado inflación, que se retrotrae al Big Bang. En esta fase el universo se infló muy rápido... A. Linde ha mostrado que si tenemos un universo inflacionario como este las fluctuaciones cuánticas causan que cree

27 Cursivas nuestras. El texto original fue recogido y traducido en 1928 por Teuira Henry, y publicado en Honolulu. Es comentado en Monberg (1956, 262), de donde lo cito. Monberg explica que "Aunque encontramos muchas referencias a la creación y muchas historias al respecto en las Islas de la Sociedad (Polinesia), solo muy pocos autores poseen textos originales o sus traducciones para ofrecernos... Henry nos suministra dos variantes" (1956, 261). El texto citado es un extracto de la primera, la más completa.

28 Cuenta con importantes defensores (Kip Thorne) y detractores (Stephen Hawking). También es debatida arduamente entre los filósofos, habiendo quienes la defienden (David Lewis) y quienes la atacan (Paul Horwich). He argumentado que tales viajes son efectivamente posibles (Romerales, 2009, 51 y ss.). 
burbujas, universos bebé, como las ramas que brotan de un árbol. Cada rama crece hasta llegar a ser tan grande como el tronco y de ella misma brotan sus propias ramas ulteriores. Podríamos preguntarnos, sin embargo, de dónde procede el tronco. Li Xin Li y yo propusimos que una de las ramas recula y crece hasta convertirse en el tronco original. Este es un modelo donde el universo es su propia madre. Un modelo con un pequeño bucle temporal en el mismo inicio $^{29}$.

Peculiares, como resultan ser estos últimos textos cosmogónicos citados, parecen encajar más bien dentro de una metafísica monista. El Tao es uno y único. El Vacío del Rg Veda también. Y Tảaroa, que actuó en soledad, siendo su propio progenitor, es quizá la máxima expresión del monismo. En suma, todos estos relatos cosmogónicos, que podríamos denominar, según el caso, abstractos, interrogativos o paradójicos, representan una metafísica que, en mi opinión, podemos calificar de monista.

\section{Conclusión: la lección de las cosmogonías}

Como filósofos, ¿qué conclusiones podemos extraer de este amplio abanico de relatos cosmogónicos de tan diversas tradiciones, lugares y épocas? En primer lugar, que existen dos líneas de respuesta claramente discernibles: las monistas y las pluralistas (dualistas en su mayoría), que surgen, respectivamente, del anhelo explicativo - que exige máxima reducción a unidad-y de la dificultad de explicar el surgimiento de la multiplicidad si la pura unidad es la realidad absoluta. Ante tal dificultad, las concepciones monistas tienden a admitir una cierta alteridad ínsita en la realidad originaria, porque un monismo radical (Parménides, Shánkara, etc.) niega la realidad del devenir, del universo y de la multiplicidad, y, por lo tanto, excluye completamente cualquier cosmogonía. Correlativamente, varias propuestas pluralistas, y singularmente las dualistas, tienden a admitir algún estado inicial, o estadio, de indiferenciación de sus dos principios que representa una suerte de fusión u homogeneización de aquello que, en última instancia, es plural. Esto hace que en muchos relatos exista una importante y a la vez difícil ambigüedad a la hora de interpretarlos como últimamente monistas o dualistas.

29 En una entrevista concedida a D. Vinkovic (Vinkovic, 2002). Gott desarrolla el tema con detalle en su libro Los viajes en el tiempo (2003, 211-218). 
Pero, en segundo lugar, en todos los textos subyace una intuición muy profunda: que el universo ha tenido un origen, una evolución y un desarrollo a partir de su momento inicial, de forma que el universo actual es muy distinto de como fue al inicio de los tiempos ${ }^{30}$ (que este origen sea único en el tiempo y último -que haya un Alfa y un Omega- o bien que existan innumerables ciclos temporales, un eterno retorno, es algo en lo que difieren las tradiciones del Oriente Medio y las del Extremo Oriente, que influyeron en el estoicismo). Tal intuición no es ineludible, porque a la observación al alcance de los humanos antes de la invención de los telescopios el universo se nos presenta como algo ordenado y estable, regido por movimientos regulares de los cuerpos celestes. De modo que esta concepción evolutiva constituye la profunda y subyacente afinidad ontológica entre todas las cosmogonías, la intuición compartida por todas ellas (el hecho mismo de que haya habido una génesis del cosmos) y, hay que recordar, por todas las cosmologías actuales, por muy diversas que sean entre sí. Es cierto que esta profunda convicción no es estrictamente universal. Aristóteles no participaba de ella. Tampoco Einstein, quien estaba convencido de que el universo es eterno y de que siempre permanece en un estado similar a escala global, como postuló A. Hoyle hace seis décadas con su teoría del estado estacionario. Si esta intuición mayoritariamente compartida por la humanidad significa algo, si no se trata simplemente de una mera casualidad, si responde a una profunda verdad metafísica cuya presencia se nos impone, solo quien esté arriba lo sabe. ¿O ni siquiera Él lo sabe?

30 Platón en el Timeo (28b) da su razón de esta intuición: "En cuanto al universo entero... hay que investigar en primer lugar: si ha sido siempre, sin tener ningún principio de generación, o si se generó comenzando de algún principio. Es generado, pues es visible y tangible, ya que tiene un cuerpo, y todas las cosas de tal clase son sensibles, y... las cosas sensibles... son generadas y engendradas" $(2010,197)$. 


\section{Fuentes}

ENUMA ELIS (2014). (Traducción de L. F. Mateu y A. Millet), Madrid: Trotta.

Hesíodo (1967). Théogonie, Paris: Belles Lettres.

(2006). Theogony (ed. y trad. G. W. Most). Cambridge (Mass.), Loeb Classical Lib.: Harvard U. P.

(2014). Obras (ed. bilingüe de J. A. Fernández Delgado), Madrid: CSIC.

Platón (2010). Timeo, (ed. bilingüe de J. M. Zamora), Madrid: Abada.

POPOL VUH (2008). (Ed. de M. Rivera), Madrid: Trotta.

TAo Te Ching. Los libros del TAO (2006). (Ed. bilingüe de Iñaki Preciado), Madrid: Trotta.

THE RIG VEDA (2014). (Ed. y trad. S. W. Jamison \& J. P. Brereton), Oxford: Oxford University Press (3 Vols.).

UPANISHADS (1995). (Trad. D. de Palma), Madrid: Trotta.

VISNÚ PURANA (1840). (Trad. H. H. Wilson), London: John Murray.

\section{Bibliografía}

Agud, A. (1995). Pensamiento y cultura en la Antigua India, Madrid: Akal.

Alonso, E. \& Romerales, E. (2009). Los viajes en el tiempo. Un enfoque multidisciplinar, Madrid: UAM Ediciones.

Arnau, J. (2012). Cosmologías de la India, México: F.C.E.

Brereton, J. P. (1999). «Edifying Puzzlement. Rgveda 10, 129 and the Uses of Enigma». Journal of the American Oriental Society, Vol. 119, 248-260.

BotтÉRo, J. (2001). La religión más antigua: Mesopotamia, Madrid: Trotta.

Bottéro, J. \& Kramer, S. N (2004). Cuando los dioses hacían de hombres. Mitología mesopotámica, Madrid: Akal.

Davidson, H. R. E. (1965). Gods and Myths of Northern Europe, London: Penguin.

Eliade, M. (1979). Historia de las ideas y de las creencias religiosas. Vol. II: De Gautama Buda al triunfo del cristianismo, Madrid: Cristiandad.

(1980). Historia de las ideas y de las creencias religiosas. Vol. IV: Las religiones en sus textos, Madrid: Cristiandad.

ÉNDOXA: Series Filosóficas, n. ${ }^{\circ}$ 36, 2015, pp. 11-30. UNED, Madrid 
Eliade, M. \& Jones, L. (eds.) (2005). Encyclopedia of Religion, 2a ed., New York: Macmillan (15 Vols.).

Foster, B. R. (2007). «Mesopotamia». En Hinnells (2007).

Frymer-Kensky, T. \& Pettinato, G. (2005). «Enuma Elish». En Eliade \& Jones (2005), Vol. IV, 2.809-12.

Glasenapr, H. von (1977). La filosofia de los hindúes, Barcelona: Barral.

Gotт, J. R. (2003). Los viajes en el tiempo y el universo de Einstein, Barcelona: Tusquets.

Hinnells, J. R. (2007). A Handbook of Ancient Religions, Cambridge: Cambridge Univ. Press.

Ilárraz, F. G. \& Pujol, O. (ed. y trad.) (2003). La sabiduría del bosque. Antología de las principales Upanishads, Madrid: Trotta.

Lindow, J. (2002). Norse Mythology: A Guide to Gods, Heroes, Rituals and Beliefs, Oxford: Oxford University Press.

LitTleton, C. S. (2004). Mitología, Barcelona: Blume.

Moberg, T. (1956). «Ta'aroa in the creation myths of the Society Islands». The Journal of the Polynesian Society. Vol. 65, No 3, 253-281.

Romerales, E. (2009). «¿Viajes trans-temporales o viajes trans-mundanos?». En Alonso \& Romerales (2009), 51-72.

VINKovic, D. (2002). "Interview to Richard Gott III", http://vinkovic.org/Projects/ PopularScience/Gott_interview/J.Richard.Gott.III.eng.html

Recibido: 7/05/2015

Aceptado: 2/06/2015

Este trabajo se encuentra bajo una licencia de Creative Commons ReconocimientoNoComercial-SinObraDerivada 4.0

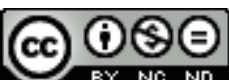

ÉNDOXA: Series Filosóficas, n. ${ }^{\circ}$ 36, 2015, pp. 11-30. UNED, Madrid 
